\title{
Anomaly Detection and Degradation Prediction of MOSFET
}

\author{
Li-Feng Wu, ${ }^{1,2}$ Yong Guan, ${ }^{1,2}$ Xiao-Juan $\mathrm{Li}^{1,2}$ and Jie $\mathrm{Ma}^{3}$ \\ ${ }^{1}$ College of Information Engineering, Capital Normal University, Beijing 100048, China \\ ${ }^{2}$ Beijing Engineering Research Center of High Reliable Embedded System, Capital Normal University, Beijing 100048, China \\ ${ }^{3}$ School of Automation, Beijing Information Science and Technology University, Beijing 100192, China
}

Correspondence should be addressed to Li-Feng Wu; wooleef@gmail.com

Received 12 September 2014; Accepted 24 December 2014

Academic Editor: Gang Li

Copyright (C) $2015 \mathrm{Li}$-Feng Wu et al. This is an open access article distributed under the Creative Commons Attribution License, which permits unrestricted use, distribution, and reproduction in any medium, provided the original work is properly cited.

\begin{abstract}
The MOSFET is an important power electronic transistor widely used in electrical systems. Its reliability has an effect on the performance of systems. In this paper, the failure models and mechanisms of MOSFETs are briefly analyzed. The on-resistance $\left(R_{\text {on }}\right)$ is the key failure precursor parameter representing the degree of degradation. Based on the experimental data, a nonlinear dualexponential degradation model for MOSFETs is obtained. Then, we present an approach for MOSFET degradation state prediction using a strong tract filter based on the obtained degradation model. Lastly, the proposed algorithm is shown to perform effectively on experimental data. Thus, it can provide early warning and enhance the reliability of electrical systems.
\end{abstract}

\section{Introduction}

Electrical systems are being used in nearly every field, and the reliability of systems is of greater concern than ever. Electrical systems are often subjected to abrupt operating conditions or aging, which can lead to shortened lifetimes or the failure of systems that result in enormous losses or casualties. The metal-oxide-semiconductor field-effect transistor (MOSFET) is a critical component widely used in electrical systems. Over $34 \%$ of failures of electrical systems are due to power failure, and a majority of these are due to MOSFET failure. Thus, more people are paying attention to how to improve MOSFET reliability.

In order to improve the performance of MOSFETs, many researchers are producing technical papers [1-3]. Unfortunately, these methods do not take into account the effect of environmental impacts and operation profiles. Condition based maintenance (CBM) has the advantage of timely detection of problems. It takes corresponding measurements to make some effectively prevent failures before they occur. Real-time MOSFET state detection and degradation prediction is an important topic for researchers.

There are many approaches to MOSFET state detection and degradation prediction that can be divided into two categories: physics-of-failure (PoF) methods and data-driven methods. PoF utilizes knowledge of a power electronic device's life cycle loading and failure mechanisms to perform reliability design and assessment. PoF-based prognostics requires knowledge of the actual application conditions and failure models. It is difficult to get a PoF model for a complex system. On the other hand, data-driven methods have been widely used due to their flexibility in application. Data-driven methods can predict the degradation state of a device by collecting data under actual conditions.

Extracting data from failure precursor parameter is the first task in degradation prediction. The ring signal has been used as a precursor feature to predict the health state of components [4]. This paper analyses the degradation of MOSFETs by characterizing source oscillator signals [5]. This degradation characteristic was extracted using an online nonintrusive method based on the Volterra series to estimate the health state [6]. However, it requires a long time to collect degradation process data at room temperature. Therefore, many studies use external stresses, such as thermal stress, local current overstress, and electrical overstress, to age devices so as to find other indicators of failure [7-9].

Many experiments have shown that an increase in junction temperature will lead to die-attach degradation; this degradation can be estimated by the increase of on-resistance [10]. Celaya et al. [10] developed an accelerated aging system 
TABLE 1: Typical failure modes [12].

\begin{tabular}{lcccc}
\hline \multirow{2}{*}{ Elements of the package } & & \multicolumn{2}{c}{ Environmental factors and electrical stress } \\
& Humidity & Ambient temperature & Power cycle & Electrical stress \\
\hline Shell & $\mathrm{J}$ & $\mathrm{U}$ & - & $\mathrm{A}, \mathrm{R}, \mathrm{L}$ \\
Chip & $\mathrm{J}$ & $\mathrm{X}, \mathrm{T}, \mathrm{Z}, \mathrm{J}, \mathrm{AD}, \mathrm{AN}, \mathrm{AM}$ & $\mathrm{A}, \mathrm{C}, \mathrm{E}, \mathrm{R}, \mathrm{L}$ & $\mathrm{J}, \mathrm{K}, \mathrm{M}, \mathrm{X}, \mathrm{T}$ \\
Adhesive layer & $\mathrm{J}, \mathrm{K}$ & $\mathrm{U}$ & $\mathrm{A}, \mathrm{C}, \mathrm{B}, \mathrm{Q}, \mathrm{E}, \mathrm{R}, \mathrm{L}, \mathrm{M}$ & - \\
Lead interconnect & $\mathrm{J}, \mathrm{E}$ & $\mathrm{M}$ & $\mathrm{J}, \mathrm{M}, \mathrm{X}$ \\
\hline
\end{tabular}

A: brittle fracture failure; C: plastic failure; AN: secondary breakdown; E: gum-off; AM: overheating stress breakdown; B: medium yield; Q: elastic deformation; X: EOS/ESD; J: corrosion; K: crystal which is too large; M: penetration and diffusion; L: increased fatigue crack depth; R: fatigue cracks; T: electromigration; Z: metallic material migration; U: oxide layer failure; AD: TDDB breakdown.

TABLE 2: Power MOSFET parameter drift failure mode and main failure mechanism [13].

\begin{tabular}{|c|c|}
\hline Failure mode & Failure mechanism \\
\hline $\begin{array}{l}\text { Threshold voltage } \\
\text { shift }\end{array}$ & $\begin{array}{l}\text { Hot carrier injection effect; ionizing radiation-induced valence bond breakage of gate silicon dioxide, } \\
\text { producing positive space charge; PBTI effect }\end{array}$ \\
\hline $\begin{array}{l}\text { Channel resistance } \\
\text { drift }\end{array}$ & Hot carrier injection effect; channel layer breakdown leading to a negative drift of channel resistance \\
\hline Transconductance fall & Channel carrier mobility decreases due to interface scattering; ray radiation; hot carrier injection effect \\
\hline Gate breakdown & $\begin{array}{l}\text { Time-dependent dielectric breakdown (TDDB); electrostatic discharge; electromagnetic pulse or surge } \\
\text { voltage; iron leakage; chemical reaction of aluminum and silica }\end{array}$ \\
\hline $\begin{array}{l}\text { Noise coefficient } \\
\text { increases }\end{array}$ & Radiation; metallization electromigration \\
\hline $\begin{array}{l}\text { Ohmic contact } \\
\text { degradation }\end{array}$ & Thermoelectric migration \\
\hline
\end{tabular}

for gate-controlled power transistors and collected degradation data from MOSFETs and employed an extended Kalman filter method for the prediction of the remaining life of power MOSFETs. These studies have made important contributions to MOSFET technology $[9,11]$. Based on the above research and taking advantage of on-resistance data, this paper presents a degradation prediction method for MOSFETs based on a strong track filter.

This paper is organized into four sections. In Section 2, the failure modes and failure mechanisms of MOSFETs are introduced and analyzed. Then, a degradation model based on experimental data and a degradation estimation method using a strong track filter are obtained. Section 3 presents and discusses the results. Finally, conclusions are drawn in Section 4.

\section{Methods}

2.1. Degradation Mechanism of MOSFETs. During the life cycle of a MOSFET, it will be subject to various complex loading conditions, including temperature, humidity, and vibration. MOSFET failure modes are divided into two kinds: package structural failure and parameter drift failure. These are shown in Tables 1 and 2, respectively.

Temperature is known to have a significant impact on the performance of power electronic devices. About $55 \%$ of the failures are due to high temperatures and temperature cycling. Although there are many failure models, MOSFET failure is mainly due to temperature. Temperature is an important factor that critically affects the life of MOSFETs. Thus, we consider the failure parameters under temperature.
2.2. Model of Degradation of MOSFET. The on-resistance of a MOSFET is a key characteristic parameter to indicate the degree of degradation. The degradation data used in this paper derives from [10]. We fit the curves for the MOSFETs using MATLAB, as shown in Figure 1. In Figure 1, A and B are the fitting curves. From the fitting, we found that the degradation process of the MOSFET can be expressed as a nonlinear dual-exponential model, as shown in

$$
R=a e^{b t}+c e^{d t}
$$

where $R$ is the increase of on-resistance due to aging, $t$ is the aging time, and $a, b, c$, and $d$ are the model parameters, respectively.

To demonstrate the effectiveness of the model, two groups' degradation data (\#14 and \#36) were used, as discussed in Section 3.

2.3. Strong Track Filter. A large class of nonlinear discretetime systems can be represented by the state equation and observation equation as follows:

$$
\begin{gathered}
x_{i}=f\left(u_{i-1}, x_{i-1}\right)+\xi_{i-1}, \\
y_{i}=g\left(x_{i}\right)+\eta_{i},
\end{gathered}
$$

where $x$ is the discrete-time variable; $x \in R^{n}$ is the state vector; $u \in R^{p}$ is the input vector; $y \in R^{m}$ is the output vector.

The nonlinear function $f: R^{p} \times R^{n} \rightarrow R^{n}, g: R^{n} \times R^{m}$ has first-order continuous partial derivatives on states where $\xi_{i-1} \sim\left(0, Q_{i-1}\right)$ is the Gaussian noise with zero mean and standard deviation $Q_{i-1}$ and $\eta_{i} \sim\left(0, R_{i}\right)$ is the Gaussian noise 


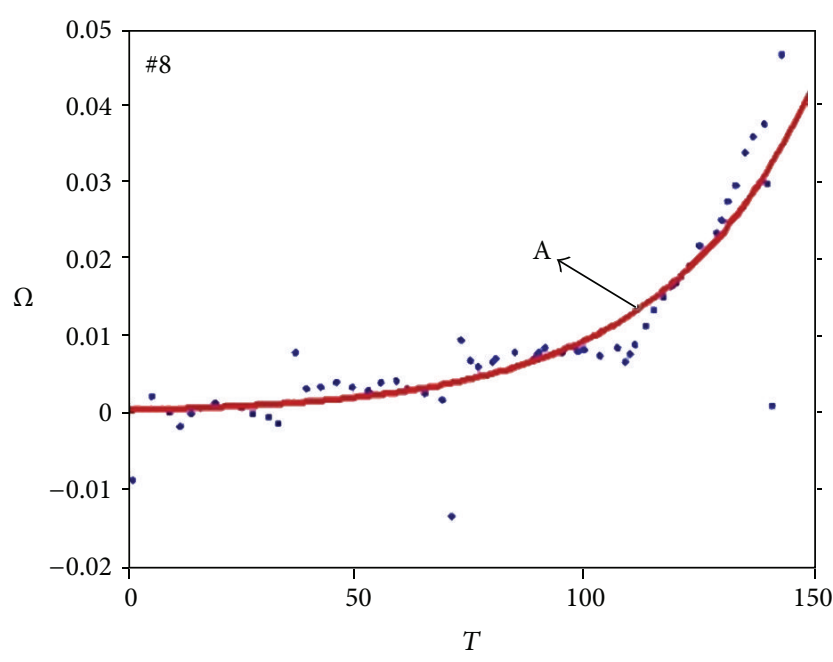

(a)

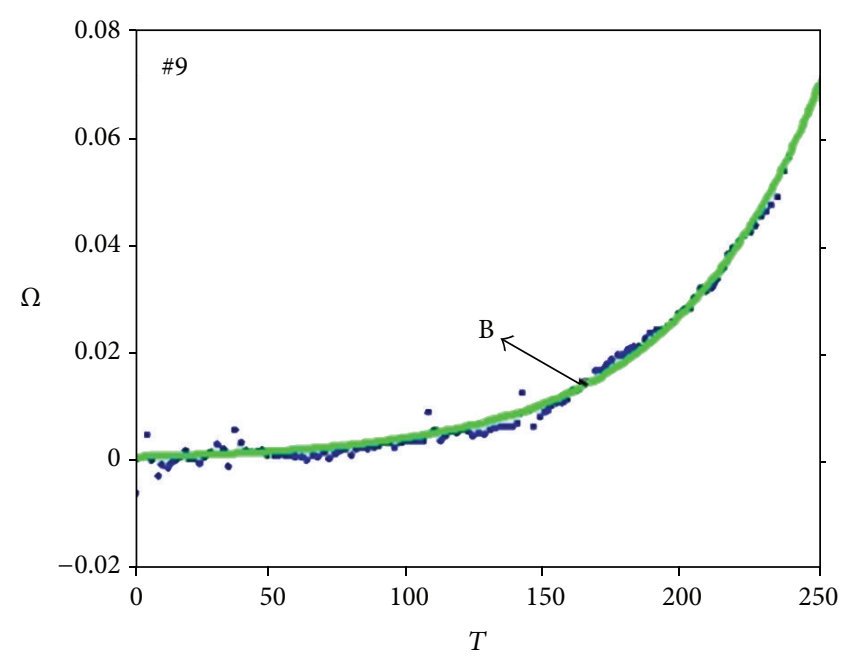

(b)

FIgURE 1: Degradation data and fitting curves of a MOSFET.

with zero mean and standard deviation $R_{i} . x_{0} \sim\left(a_{0}, P_{0}\right)$ is the Gaussian noise with $a_{0}$ mean and standard deviation $P_{0}$. $X=\left\{x_{0}, x_{1}, x_{2}, \ldots, x_{i-1}\right\}$ is the data until $t_{i}$.

Here, the estimation value, $x_{i}$, and the estimation variance are expressed: $\widehat{x}_{i}=E\left[\begin{array}{lll}x_{0} & X_{0: i}\end{array}\right]$ and $P_{i \mid i}=\operatorname{Var}\left(x_{i} \mid X_{0: i}\right)$, respectively.

So, the state prediction equation is given by the following expression:

$$
p\left(x_{i} \mid X_{0: i}\right)=\int p\left(x_{i} x_{i-1}\right) p\left(x_{i-1} \mid X_{0: i}\right) d x_{i-1} .
$$

The STF was firstly proposed by Zhou et al. in [14]. The algorithm based on the extended Kalman filter is a suboptimal fading factor $\lambda(k+1)$ that can be described as follows [14].

(1) Initialization. Consider

$$
\widehat{x}_{0}=a_{0}, P_{0}, \alpha, \beta,
$$

where $\alpha$ and $\beta$ are the softening factor and the forgetting factor, respectively.

Let $\alpha=1.1, \beta=0.95$.

(2) Calculation of the Attenuation Factor. Consider

$$
\begin{gathered}
V_{0}\left(t_{i}\right)= \begin{cases}\gamma^{2}\left(t_{1}\right), & i=1, \\
\frac{\rho V_{0}\left(t_{i-1}\right)+\gamma^{2}\left(t_{i}\right)}{1+\rho}, & i>1,\end{cases} \\
\gamma\left(t_{i}\right)=y_{i}-y_{i-1}-\hat{y}_{i-1}\left(t_{i}-t_{i-1}\right), \\
B\left(t_{i}\right)=V_{0}\left(t_{i}\right)-Q\left(t_{i}-t_{i-1}\right)^{2}-\alpha \sigma^{2}\left(t_{i}-t_{i-1}\right), \\
C\left(t_{i}\right)=P_{i-1 \mid i-1}\left(t_{i}-t_{i-1}\right)^{2}, \\
v_{0}=\frac{B\left(t_{i}\right)}{C\left(t_{i}\right)}, \\
v\left(t_{i}\right)= \begin{cases}v_{0}, & v_{0} \geq 1, \\
1, & v_{0}<1 .\end{cases}
\end{gathered}
$$

(3) State Estimation. Consider

$$
\begin{gathered}
P_{i \mid i-1}=v\left(t_{i}\right) P_{i-1 \mid i-1}+Q, \\
K_{i}=\left(t_{i}-t_{i-1}\right)^{2} P_{i \mid i-1}+\sigma^{2}\left(t_{i}-t_{i-1}\right), \\
\hat{y}_{i}=\hat{y}_{i-1}+P_{i \mid i-1}\left(t_{i}-t_{i-1}\right) K_{i}^{-1}\left(y_{i}-y_{i-1}-\hat{y}_{i-1}\left(t_{i}-t_{i-1}\right)\right),
\end{gathered}
$$

where $K_{i}$ is the filter gain.

(4) Measurement Update. Consider

$$
P_{i \mid i}=P_{i \mid i-1}-P_{i \mid i-1}\left(t_{i}-t_{i-1}\right)^{2} K_{i}^{-1} P_{i \mid i-1} .
$$

2.4. Degradation Prediction of MOSFET Based on Strong Track Filter. According to the above analysis, the MOSFET degradation process can be expressed as follows.

The System Transition. Consider

$$
\begin{aligned}
a_{i} & =a_{i-1}+\theta_{a}, \\
b_{i} & =b_{i-1}+\theta_{b}, \\
c_{i} & =c_{i-1}+\theta_{c}, \\
d_{i} & =d_{i-1}+\theta_{d} .
\end{aligned}
$$

Measurement Function. Consider

$$
R_{i}=a_{i} e^{b_{i} t_{i}}+c_{i} e^{d_{i} t_{i}}+\eta_{i}
$$

Now the parameters must be determined. According to the STF, the algorithm can be described as in Figure 2. The process includes training, prediction, and evaluation. Training involves using real data to determine parameters. The initial parameters are selected according to the calculation results of (8) and (9). We chose three parameters (coefficient of 


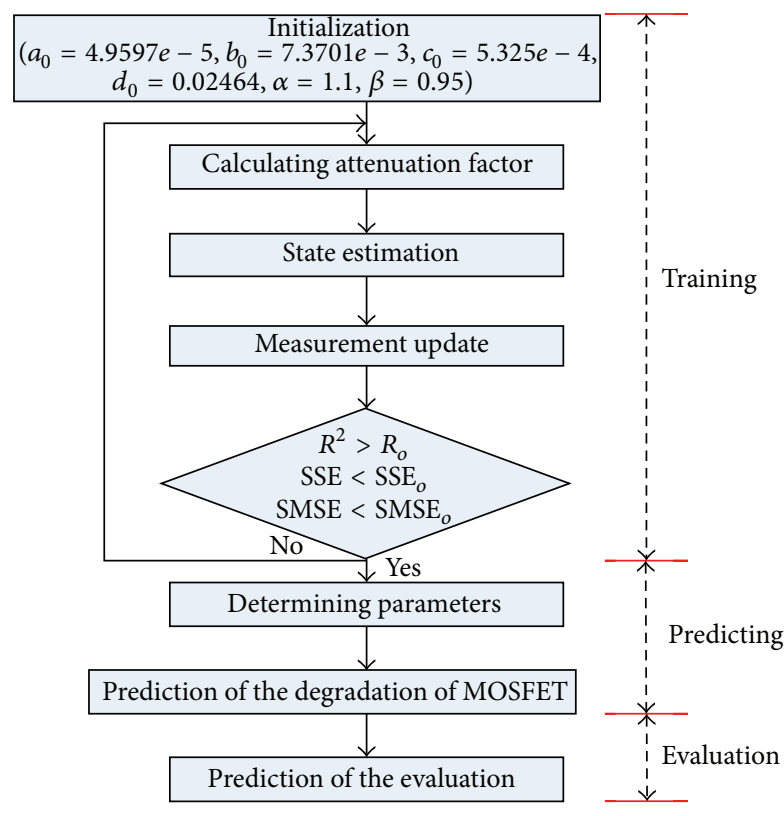

FIGURE 2: Degradation of MOSFET prediction process.

determination ( $R$-square), root mean square error (RMSE), and sum square error (SSE)) to evaluate the results. The root mean square error (RMSE) is defined as

$$
\mathrm{RMSE}=\sqrt{\frac{1}{T} \sum_{i=1}^{T}\left(\widehat{R}_{i}-R_{i}\right)^{2}}
$$

The coefficient of determination is defined as

$$
R^{2}=\frac{\sum\left(\widehat{R}_{i}-\bar{R}\right)^{2}}{\sum\left(R_{i}-\bar{R}\right)^{2}}
$$

where $R_{i}$ denotes the observed values of the dependent variable. $\bar{R}$ is the mean, and $\widehat{R}_{i}$ is the fitted value, respectively. $R_{0}, \mathrm{SSE}_{0}$, and $\mathrm{SMSE}_{0}$ are given by real requirement. When $R-$ square, RMSE, and SSE meet the requirement, the training is over. Then, according to the measurement function and threshold, we can estimate the MOSFET degradation trend and the remaining useful life. At last, we evaluate the results by comparing the prediction and real data.

\section{Results and Discussion}

Figure 3 shows the prognostic results of MOSFET \#14 under the degradation model proposed. Using the data (before $118 \mathrm{~h}$ ) as training data and based on the model and the present method, we got the prediction function. In order to evaluate the prediction, we calculated the three important statistical indicators: $R$-square, SSE, and RMSE. The results are shown in Table 1. From the results, the SSE and RMSE values are 0.0002868 and 0.002349 , respectively. The $R$-square value is 0.9696 (Table 3). From the results, it can be seen that the model and method were effective.

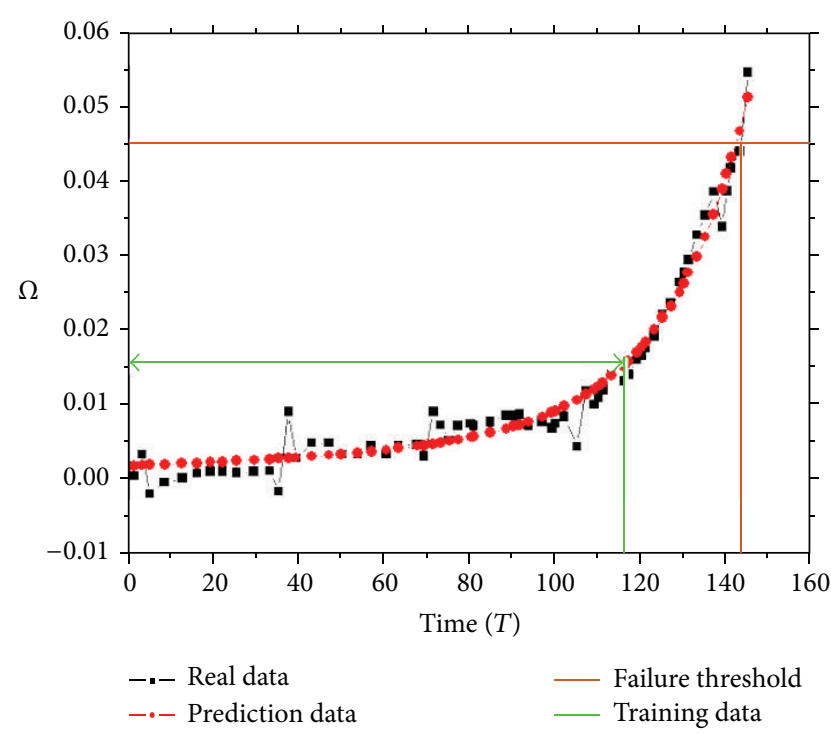

FIgURE 3: Comparison of experimental and predicted results of MOSFET \#14.

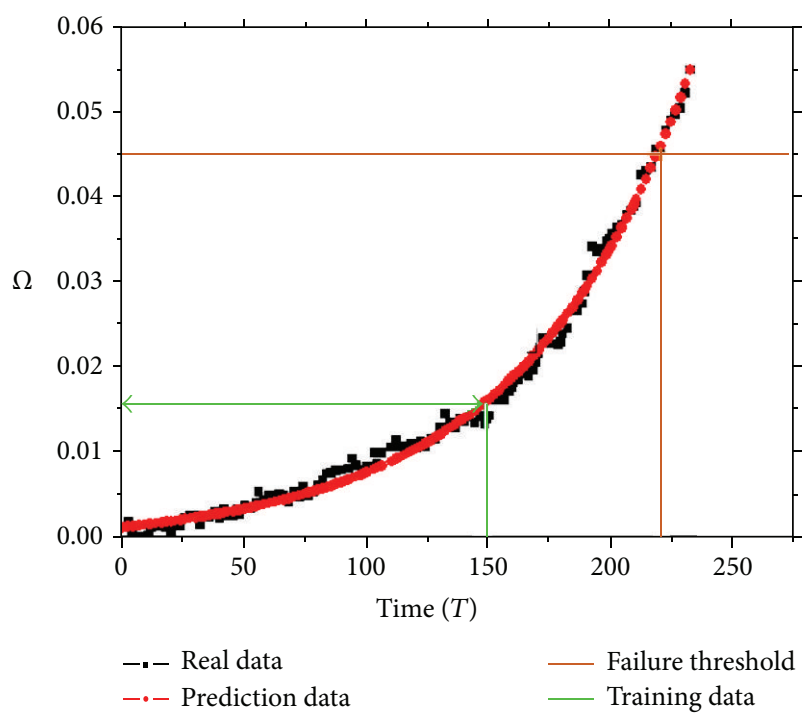

FIGURE 4: Comparison of experimental and predicted results of MOSFET \#36.

TABLE 3: The evaluation of predicted results.

\begin{tabular}{lccc}
\hline MOSFET & $R$-square & RMSE & SSE \\
\hline$\# 14$ & 0.9696 & 0.002349 & 0.0002868 \\
$\# 36$ & 0.9919 & 0.001326 & 0.0002023 \\
\hline
\end{tabular}

Figure 4 shows the prognostic results of MOSFET \#36 under the degradation model proposed. We used the data (before $150 \mathrm{~h}$ ) as the training data and proposed the method under the degradation model to compute the prediction function parameters. Then, taking advantage of the function and the defined failure threshold, we can get the degradation trend. The $R$-square, SSE, and RMSE are 0.9919, 0.0002023, and 0.001326 , respectively, and are shown in Table 1. From the 
results, one can see good agreement between the real data and the computed data.

\section{Conclusions}

MOSFETs play a critical role in the reliability of power electronics. Investigating the degradation method of MOSFETs is the first step in realizing prognostics and health management for power electronics systems. According to the precursor failures by experiment data, a degradation model of a MOSFET has been obtained, and the method to estimate the degradation of the MOSFET has been proposed using a strong track filter. The results show that the model is consistent with the real degradation trend. The prediction revealed that the method is more efficient. With the aim of comparing the prediction and real data, the coefficient of determination ( $R$-square), sum square error (SSE), and root mean square error (RMSE) were calculated to evaluate the model and method. From the results, lower SSE and RMSE values and higher $R$-square values indicate that the model and method are effective.

\section{Conflict of Interests}

The authors declare that there is no conflict of interests regarding the publication of this paper.

\section{Acknowledgments}

This work was supported by the National Natural Science Foundation of China (no. 61202027, no. 61273173), the National Key Technology R\&D Project (no. 2012DFA11340), and the Beijing Natural Science Foundation of China (no. 4122015). The degradation data used in this paper comes from Celaya et al. experiments, and the authors thank them again.

\section{References}

[1] M. Cheralathan, C. Sampedro, F. Gámiz, and B. Iñiguez, "Analytical temperature dependent model for nanoscale double-gate MOSFETs reproducing advanced transport models," Solid-State Electronics, vol. 98, pp. 2-6, 2014.

[2] V. Kumari, M. Saxena, R. S. Gupta, and M. Gupta, "Investigation of electrostatic integrity of nanoscale dual material gate dielectric pocket silicon-on-void (DMGDPSOV) MOSFET for improved device scalability," IEEE Transactions on Nanotechnology, vol. 13, no. 4, pp. 667-675, 2014

[3] B.-I. Lee, J. M. Geum, E. S. Jung, E. G. Kang, Y.-T. Kim, and M. Y. Sung, "Analysis of lattice temperature in super junction trench gate power MOSFET as changing degree of trench etching," Journal of Semiconductor Technology and Science, vol. 14, no. 3, pp. 263-267, 2014.

[4] A. Ginart, M. J. Roemer, P. W. Kalgren, and K. Goebel, "Modeling aging effects of IGBTs in power drives by ringing characterization," in Proceedings of the International Conference on Prognostics and Health Management (PHM '08), pp. 1-7, Denver, Colo, USA, October 2008.

[5] X. Zheng, L. Wu, Y. Guan, and X. Li, "Analysis of the degradation of MOSFETs in switching mode power supply by characterizing source oscillator signals," Mathematical Problems in Engineering, vol. 2013, Article ID 302563, 7 pages, 2013.
[6] L.-F. Wu, Y. Zheng, Y. Guan, G.-H. Wang, and X.-J. Li, "A nonintrusive method for monitoring the degradation of MOSFETs," Sensors, vol. 14, no. 1, pp. 1132-1139, 2014.

[7] V. Smet, F. Forest, J.-J. Huselstein et al., "Ageing and failure modes of IGBT modules in high-temperature power cycling," IEEE Transactions on Industrial Electronics, vol. 58, no. 10, pp. 4931-4941, 2011.

[8] J. R. Celaya, V. Vashchenko, P. Wysocki, S. Saha, and K. Goebel, "Accelerated aging system for prognostics of power semiconductor devices," in Proceedings of the IEEE (AUTOTESTCON '10), vol. 4, pp. 1-6, Orlando, Fla, USA, September 2010.

[9] S. Saha, J. R. Celaya, and V. Vashchenko, "Accelerated aging with electrical overstress and prognostics for power MOSFETs," Energytech, vol. 47, pp. 1-6, 2011.

[10] J. R. Celaya, A. Saxena, C. S. Kulkarni, S. Saha, and K. Goebel, "Prognostics approach for power MOSFET under thermalstress aging," in Proceedings of the Annual Reliability and Maintainability Symposium (RAMS '12), pp. 1-6, January 2012.

[11] J. R. Celaya, P. Wysocki, V. Vashchenko, S. Saha, and K. Goebel, "Accelerated aging system for prognostics of power semiconductor devices," in Proceedings of the IEEE AUTOTESTCON, pp. 1-6, Orlando, Fla, USA, September 2010.

[12] Y. Chen, B. Sun, J.-S. Xie, and R. Kang, "Typical use environmental conditions, test conditionds and failure mechanisms of high reliability electronic components," Electronic Product Reliability and Environmental Testing, vol. 25, no. 6, pp. 23-30, 2007.

[13] Y. Wang, Z. Yu, and Z. Sun, Electronic Element Device Reliability Design, Science Publishing House, Beijing, China, 2007.

[14] D. Zhou, Y. Xi, and Z. Zhang, "Suboptimal fading extended Kalman filtering for nonlinear systems," Control and Decision, vol. 5, no. 5, pp. 1-6, 1990. 


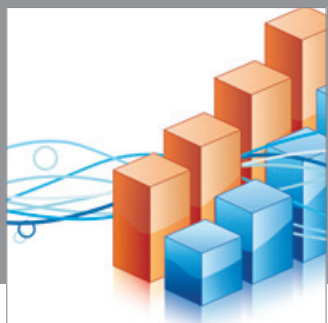

Advances in

Operations Research

mansans

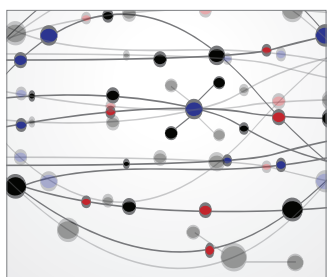

The Scientific World Journal
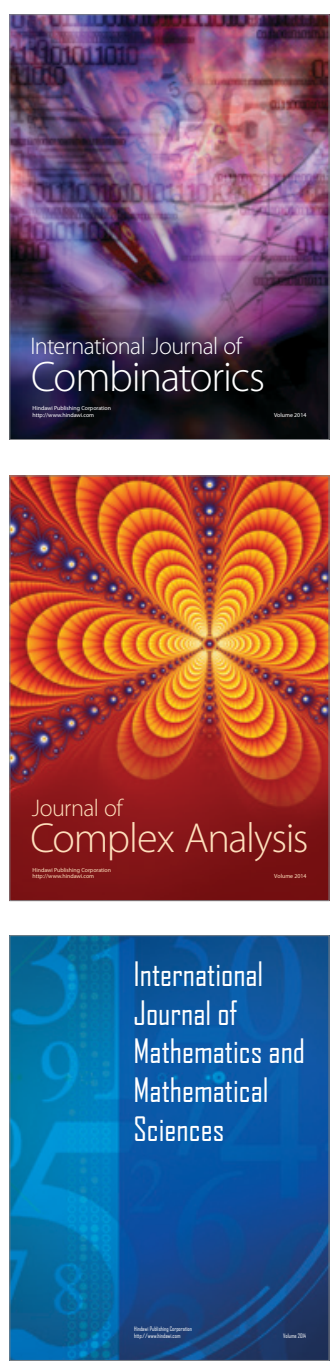
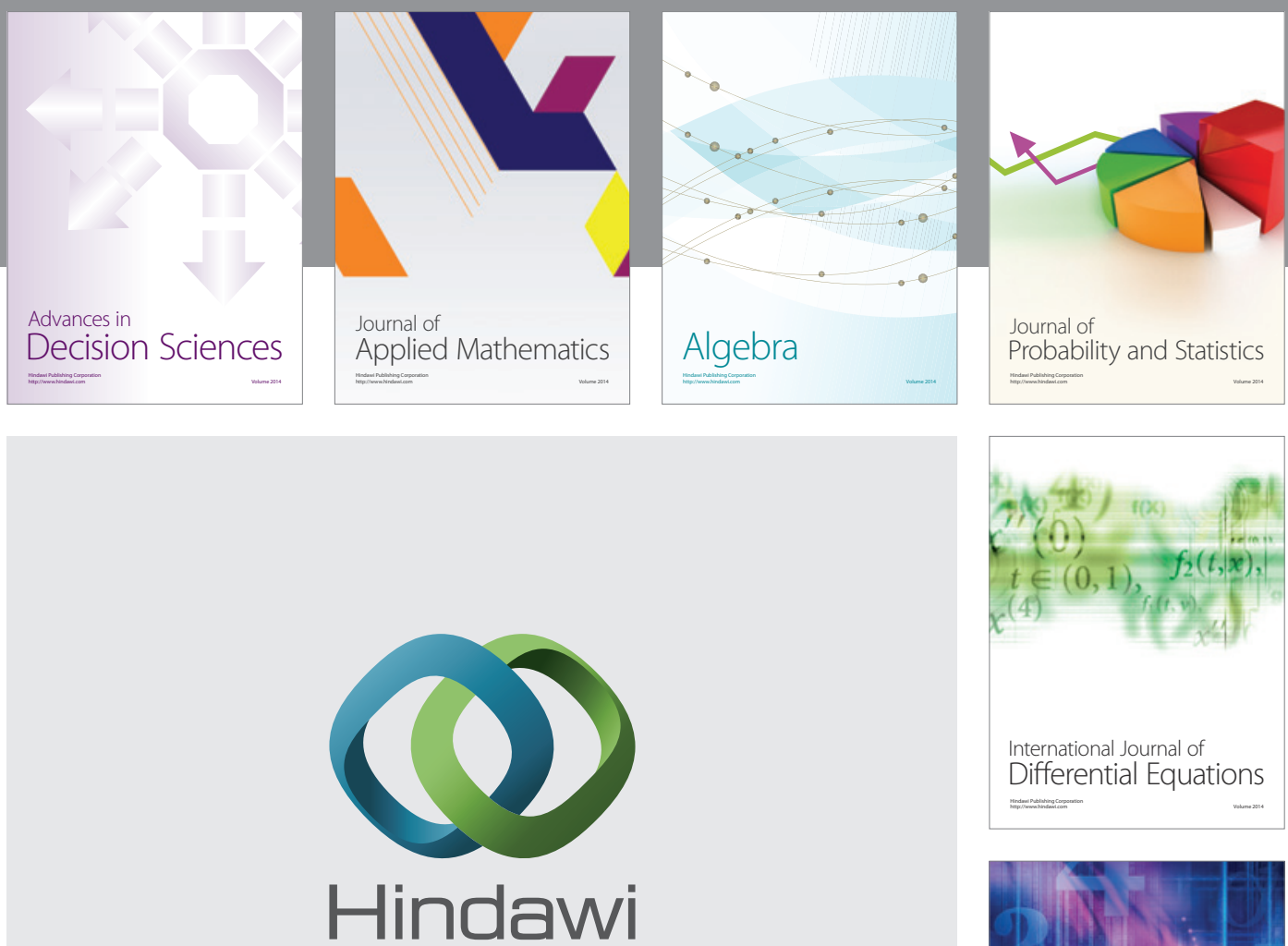

Submit your manuscripts at http://www.hindawi.com
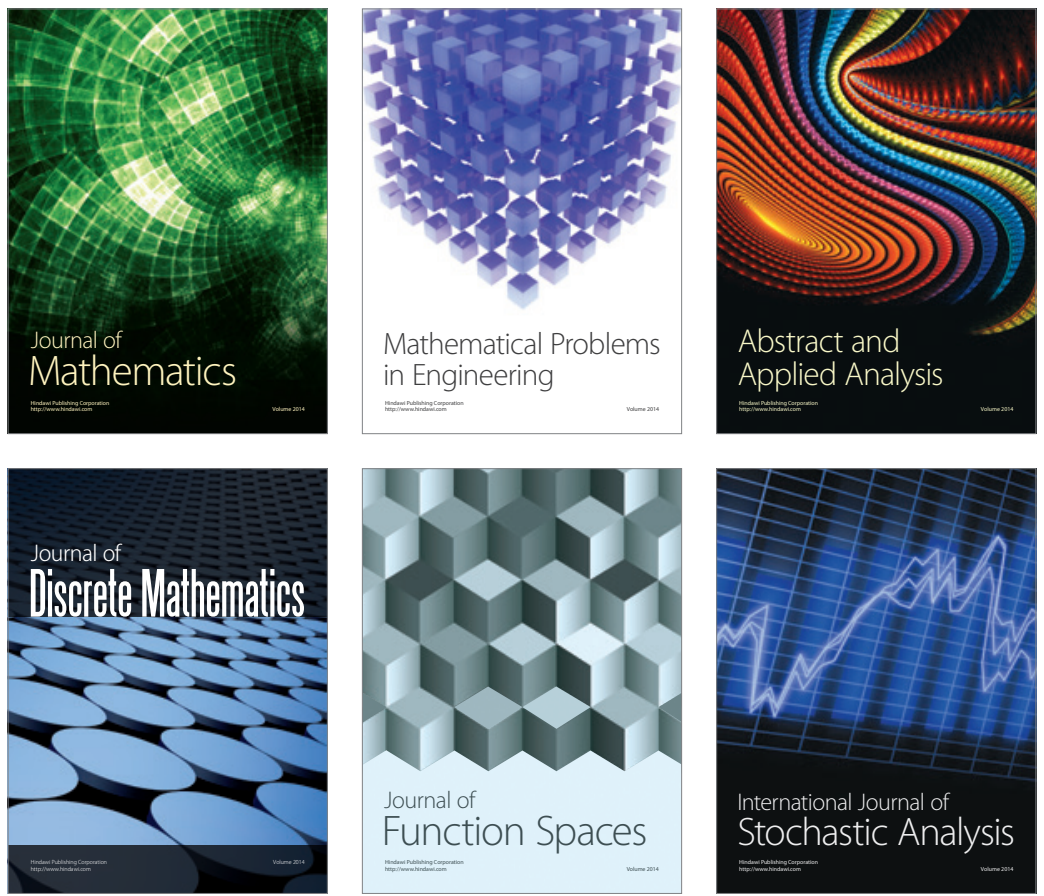

Journal of

Function Spaces

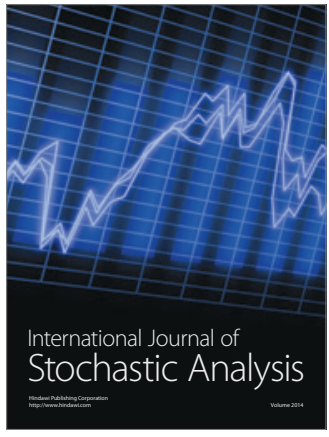

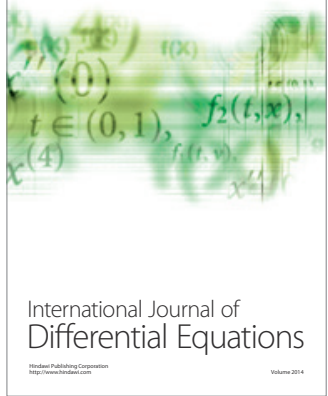
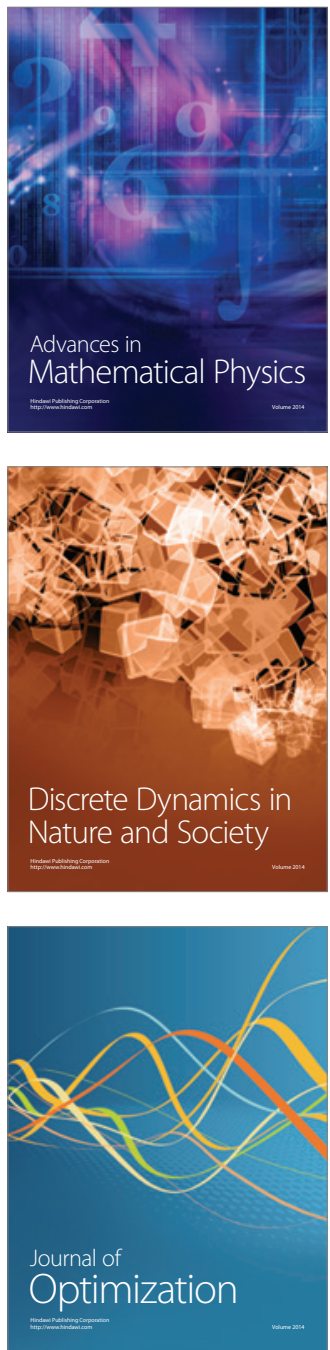